\title{
Selenium Protects Retinal Cells from Cisplatin-Induced Alterations in Carbohydrate Residues
}

\author{
Dilek Akşit ${ }^{1}$, Alper Yazıcı², Hasan Akşit ${ }^{3}$, Esin S. Sarı², Arzu Yay ${ }^{4}$, Onur Yıldız ${ }^{3}$, Adil Kılıç², Sıtkı S. Ermişş2, Kamil Seyrek \\ ${ }^{1}$ Department of Pharmacology and Toxicology, Balıkesir University School of Veterinary, Balıkesir, Turkey \\ ${ }^{2}$ Department of Ophthalmology, Balıkesir University School of Medicine, Balıkesir, Turkey \\ ${ }^{3}$ Department of Biochemistry, Balıkesir University School of Veterinary, Balıkesir, Turkey \\ ${ }^{4}$ Department of Histology and Embryology, University of Erciyes School of Medicine, Kayseri, Turkey \\ ${ }^{5}$ Department of Medicinal Biochemistry, Balıkesir University School of Medicine, Balıkesir, Turkey
}

Background: Investigate alterations in the expression and localization of carbohydrate units in rat retinal cells exposed to cisplatin toxicity.

Aims: The aim of the study was to evaluate putative protective effects of selenium on retinal cells subjected to cisplatin. Study Design: Animal experiment.

Methods: Eighteen healthy Wistar rats were divided into three equal groups: 1. Control, 2. Cisplatin and 3. Cisplatin+selenium groups. After anesthesia, the right eye of each rat was enucleated.

Results: Histochemically, retinal cells of control groups reacted with $\alpha$-2,3-bound sialic acid-specific Maackia amurensis lectin (MAA) strongly, while cisplatin reduced the staining intensity for MAA. However, selenium administration alleviated the reducing effect of cisplatin on the binding sites for MAA in retinal cells. The staining intensity for $\mathrm{N}$-acetylgalactosamine (GalNAc residues) specific Griffonia simplicifolia-1 (GSL-1) was relatively slight in control animals and cisplatin reduced this slight staining for GSL-1 further. Selenium administration mitigated the reducing effect of cisplatin on the binding sites for GSL-1. A diffuse staining for $\mathrm{N}$-acetylglucosamine (GlcNAc) specific wheat germ agglutinin (WGA) was observed throughout the retina of the control animals. In particular, cells localized in the inner plexiform and photoreceptor layers are reacted strongly with WGA. Compared to the control animals, binding sites for WGA in the retina of rats given cisplatin were remarkably decreased. However, the retinal cells of rats given selenium reacted strongly with WGA.

Conclusion: Cisplatin reduces $\alpha-2,3$-bound sialic acid, GlcNAc and GalNAc residues in certain retinal cells. However, selenium alleviates the reducing effect of cisplatin on carbohydrate residues in retinal cells.

Keywords: Cisplatin, n-acetylglucosamine, selenium, sialic acid
Selenium (Se) is a necessary trace mineral in the diet of many animals, which is known to serve a wide variety of functions in health and development, including in cancer and heart disease prevention, viral inhibition, and immune function $(1,2)$. One of its main functions is an antioxidant action involved in protection against damage caused by free radicals and oxidative stress (3). Selenoenzymes, namely glutathione peroxidase (GPX) and thioredoxin reductase (TR), are known for their antioxidant function and maintenance of redox balance (4). Se deficiency can cause metabolic dysfunction, mor- phology damage and changes in glutathione peroxidase in the livers of mouse, rabbit, trout, turkey and so on (5).

Carbohydrates function as both an energy source (glycogen) and structural elements (cellulose) in live tissues. In addition to these widely known actions, recent studies have shown that carbohydrates also have extremely important roles in cellular interactions, signal transferring and viability. They perform these functions via a protein or glycoprotein like receptors called lectins (6). The first lectin was discovered from the extracts of a plant called Ricinus comminus which caused the

Address for Correspondence: Dr. Dilek Akşit, Department of Pharmacology and Toxicology, Balıkesir University School of Veterinary, Balıkesir, Turkey

Phone: +905448329980 e-mail: dilekaksit@balikesir.edu.tr

Received: 18 May $2015 \quad$ Accepted: 7 October 2015

• DOI: 10.5152/balkanmedj.2015.155532

Available at www.balkanmedicaljournal.org

Cite this article as:

Akşit D, Yazıcı A, Akşit H, Sarı ES, Yay A, Yıldız O, et al. Selenium protects retinal cells from cisplatin-induced alterations in carbohydrate residues. Balkan Med J

2016;33:441-7 
agglutination of erythrocytes (7). Lectins are present in both plants called exogenous lectins and animals called endogenous lectins. They are synthesized by the transcription of the genes called glycogens. However, they have neither enzyme activity nor antibody properties (8). The interactions of carbohydrates and their specific lectins are involved in various physiologic processes like intercellular interactions, signal transduction, intracellular protein transport, fertilization, cellular adhesions, interferon and interleukin synthesis, infections, embryogenesis, cell hyperplasia and dysplasia, carcinogenesis, and metastasis $(9,10)$. To determine the expression and localization of carbohydrate units in different organs like skin, bone, muscle, brain, or ocular surface, numerous studies were performed (11-13). To evaluate these various carbohydrate residues, both exogenous and endogenous lectins have been used in numerous studies.

Cisplatin (cis-diamminedichloroplatinum) is a chemotherapeutic agent used in many types of cancers including cancers of the gonad, breast, lung, bladder and lymphoma (14). It causes DNA adducts, and the production of reactive oxygen species. Although very effective, its use is limited due to the side effect profile, like gonadotoxicity, nephrotoxicity, neurotoxicity, ototoxicity, retinotoxicity and bone marrow suppression $(15,16)$.

Selenium is an essential trace element that needs to be provided by the diet. It has anti-inflammatory and antioxidant properties and has been shown to be effective in cisplatinrelated toxicities and other types of tissue injuries (17-19). Se deficiency and liver damage have been widely studied; however, the effects of Se deficiency on the mechanism of retinal cells from cisplatin-induced alterations in carbohydrate residues have not been elucidated. Herein, in the present study, we determined alterations in the expression and localization of carbohydrate units in rat retinal cells exposed to cisplatin toxicity and evaluated the putative protective effect of selenium on retinal cells subjected to cisplatin.

To the best of our knowledge, there are no data on alterations in carbohydrate units such as $\mathrm{N}$-acetylglucosamine (GlcNAc), $\mathrm{N}$-acetylgalactosamine (GalNAc) and sialic acid residues in rat retina exposed to cisplatin. In the present study, to demonstrate the alterations in carbohydrate residues, we used $\alpha-2,3$-bound sialic acid-specific Maackia amurensis lectin-2 (MAA), GalNAc-specific Griffonia simplicifolia-1 (GSL-1) and GlcNAc-specific wheat germ agglutinin (WGA).

\section{MATERIALS AND METHODS}

Institutional ethics committee approval for animal studies was obtained prior to the study. All animals used in the study received care in compliance with the guidelines established by the committee. All studies with animals described herein were reviewed and approved by the Local Animal Ethics Committee (03/07/2013, 2013-13-94) and The Association for Research in Vision and Ophthalmology (ARVO) guidelines.

Animals
Eighteen healthy adult Wistar rats weighing 250-300 g were housed in 14/10 hour light/dark cycle with free access to food and water. Rats were assigned into three groups. Group $1(\mathrm{n}=6)$ received an intraperitoneal (i.p.) injection of $2.5 \mathrm{~mL}$ physiologic saline for 3 days, group $2(n=6)$ received an i.p. injection of $16 \mathrm{mg} / \mathrm{kg}$ cisplatin (Eczacıbaş1; İstanbul, Turkey) for 3 days, and group $3(\mathrm{n}=6)$ received $16 \mathrm{mg} / \mathrm{kg}$ cisplatin (Eczacıbaşı; İstanbul, Turkey) for 3 days $+1.5 \mathrm{mg} / \mathrm{kg}$ selenium twice daily via gavage (sodium selenite $98 \%$ powder, Sigma S5261), which were started 5 days prior to cisplatin injection and continued for 3 days concomitantly with cisplatin injections. At the end of the study period, the animals were anesthetized with $30 \mathrm{mg} / \mathrm{kg}$ of ketamine (Ketalar ${ }^{\circledR}$, Eczacıbaş1; İstanbul, Turkey) and $4 \mathrm{mg} / \mathrm{kg}$ xylazine (Rompun ${ }^{\circledR}$, Bayer; İstanbul, Turkey) and the right eye of each rat was enucleated. All animals were then sacrificed with high dose i.p. thiopental sodium (Pentothal, Abbott Laboratories; North Chicago, IL, USA).

\section{Immunohistochemistry for lectins}

For histological examination, eye tissues were removed, fixed in $10 \%$ formalin for $24 \mathrm{~h}$, processed by routine histological methods and embedded in paraffin blocks. Four-micrometer-thick sections of specimens were deparaffinized in xylene and dehydrated in graded alcohol (100-70\%). Slices were treated with $0.1 \%(\mathrm{w} / \mathrm{v})$ trypsin solution for $2 \mathrm{~min}$ at $37^{\circ} \mathrm{C}$ followed by a $0.3 \%$ methanol- $\mathrm{H}_{2} \mathrm{O}_{2}$ solution for $30 \mathrm{~min}$. After washing three times with PBS, the tissues were conjugated with $2 \%$ bovine albumin (BSA, Sigma) for 30 minutes, preventing nonspecific binding, and were then incubated separately with biotin-conjugated MAA, GSL-1 and WGA lectins (Vector; UK), diluted 1:200 for 1 hour at room temperature. Diaminobenzidine (DAB) was used as chromogen and hematoxylin was used as the counter stain. Negative controls were performed by replacing the lectins with PBS.

\section{Quantitative immunohistochemistry}

The mean immunoreactivity intensity was determined at five separate microscopic fields of the retina in five sections for each animal (total 30 microscopic fields) at an original magnification of $\times 400$. Presence of the positive cells is taken into consideration in the selection of the microscobing fields. The mean of immunoreactivity intensity calculated by using Image J software. 


\section{Statistical analyses}

The results were statistically analyzed with Statistical Package for the Social Sciences version 15.0 (SPSS Inc.; Chicago, IL, USA). Shapiro-Wilk test was used to evaluate the normality of distribution of the data and One-way ANOVA and PostHoc Tukey HSD tests were used for statistical comparison since the data were normally distributed. All data were given as the mean $\pm \mathrm{SD}$ (standard deviation) and $\mathrm{p}<0.05$ was considered statistically significant.

\section{RESULTS}

To determine the localization of carbohydrate units and to visualize the staining intensity, sections stained with biotinlabeled MAA, GSL-1 and WGA were examined under light microscopy. The intensities of the staining were calculated by the Image J software program.

A strong reaction was observed in control tissues stained with MAA. Positive cells were distributed over the retinal layers. In particular, the photoreceptor layer of the retina strongly stained with MAA (Figure 1). Treatment with cisplatin reduced the staining intensity for MAA drastically; however, the staining pattern remained largely unaffected (Figure 2). Data obtained using the Image $\mathrm{J}$ software program confirmed the decline in staining intensity throughout the photoreceptor layer of the retinas of rats given cisplatin. While the intensity values were $144.19 \pm 3.20$ in control animals, cisplatin treatment reduced this value significantly to $132.12 \pm 2.02(\mathrm{p}<0.05$, Table 1). Selenium alleviated the adverse effects of cisplatin on $\alpha$-2,3-bound sialic acid synthesis in the photoreceptor layer of rat retina. Similar to the control animals, strong staining was observed for MAA in the retina of rats given cisplatin and selenium together (Figure 3 ). The mean intensity value was $139.64 \pm 4.47$ in the cisplatin+selenium group.

Binding sites for biotinylated GSL-1 were relatively less common than the binding sites for biotin labeled MAA in all groups (Figure 4). In control animals, reactions with GSL-1 were evenly distributed throughout the rat retina and the intensity value was $128.63 \pm 3.20$. Similar to the sialic acid residues, GalNAc structures were also reduced by cisplatin and the adverse effects of cisplatin on the expression of GalNAc residues were mitigated by selenium (Figure 5,6). The mean intensity value of GalNAc structures in the cisplatin group was $116.42 \pm 2.02$, whereas this value in the cisplatin+selenium group increased to $123.97 \pm 3.20$ (Table 1).

Histochemically, a diffuse WGA staining of GlcNAc residues was observed throughout the retina of control animals. In particular, cells localized in the inner plexiform and photoreceptor layers reacted strongly with biotin-labeled WGA (Figure 7). This strong reaction for WGA was verified by

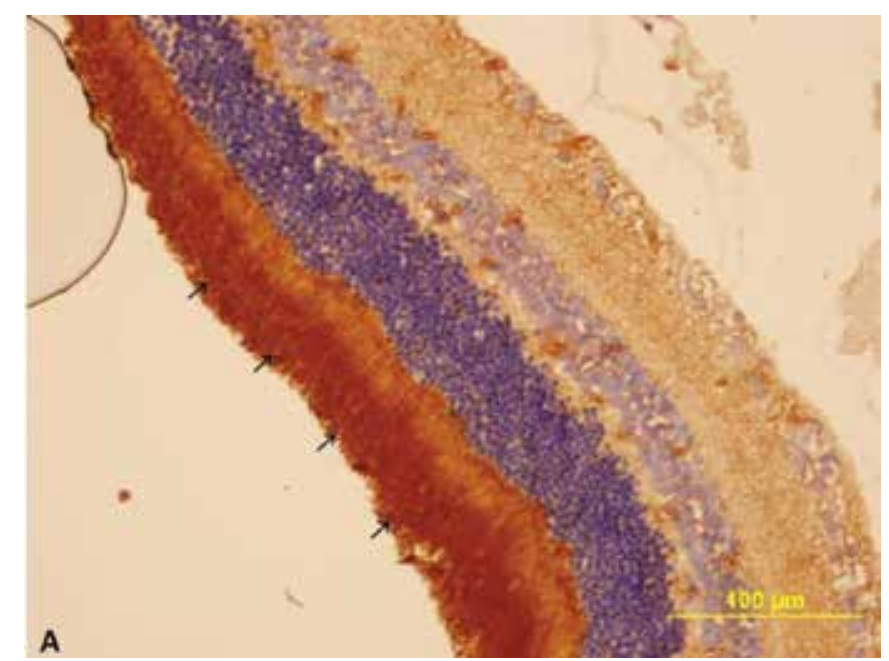

FIG. 1. MAA staining in the control group. Tissues were stained with MAA. A strong reaction was observed in control tissues stained with MAA. Positive cells were distributed over the retinal layers. In particular, the photoreceptor layer of the retina strongly stained with MAA.

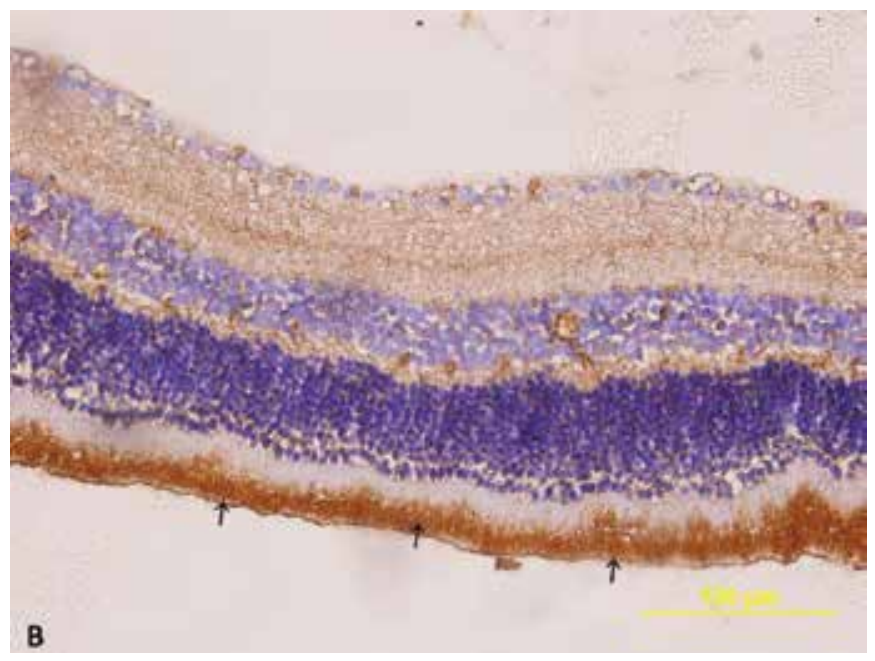

FIG. 2. MAA staining in the cisplatin group. Animals were exposed to cisplatin and tissues were stained with MAA. Treatment with cisplatin reduced the staining intensity drastically; however, the staining pattern remained largely unaffected.

TABLE 1. Immunoreactivity intensity values of control, cisplatin and cisplatin+selenium groups

\begin{tabular}{lcccc}
\hline & $\begin{array}{c}\text { Control } \\
\text { Mean } \pm \text { SD }\end{array}$ & $\begin{array}{c}\text { Cisplatin } \\
\text { Mean } \pm \text { SD }\end{array}$ & $\begin{array}{c}\text { Cisplatin }+ \text { selenium } \\
\text { Mean } \pm \text { SD }\end{array}$ & p \\
\hline MAA & $144.19 \pm 3.20^{\mathrm{a}}$ & $132.14 \pm 2.02^{\mathrm{b}}$ & $139.64 \pm 4.47^{\mathrm{ab}}$ & $<0.05$ \\
GSL-1 & $128.63 \pm 2.94^{\mathrm{a}}$ & $116.42 \pm 2.01^{\mathrm{b}}$ & $123.97 \pm 3.20^{\mathrm{ab}}$ & $<0.01$ \\
WGA & $169.91 \pm 5.92^{\mathrm{a}}$ & $156.45 \pm 3.21^{\mathrm{b}}$ & $162.58 \pm 2.61^{\mathrm{ab}}$ & $<0.05$ \\
\hline
\end{tabular}

a,b There is significant difference among groups in the same row.

SD: standard deviation; MAA: Maackia amurensis lectin; GSL-1: Griffonia simplicifolia-1; WGA: wheat germ agglutinin 


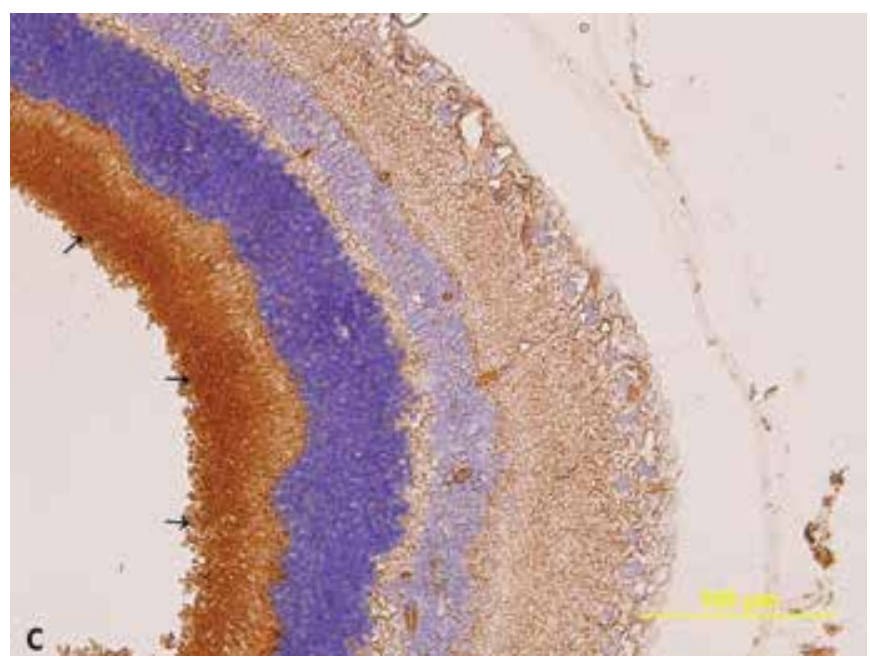

FIG. 3. MAA staining in the cisplatin + selenium group. Tissues were stained with MAA. Selenium alleviated the adverse effects of cisplatin on $\alpha-2,3-$ bound sialic acid synthesis in the photoreceptor layer of rat retina. Similar to the control animals, strong staining was observed for MAA in the retina of rats given cisplatin and selenium together.

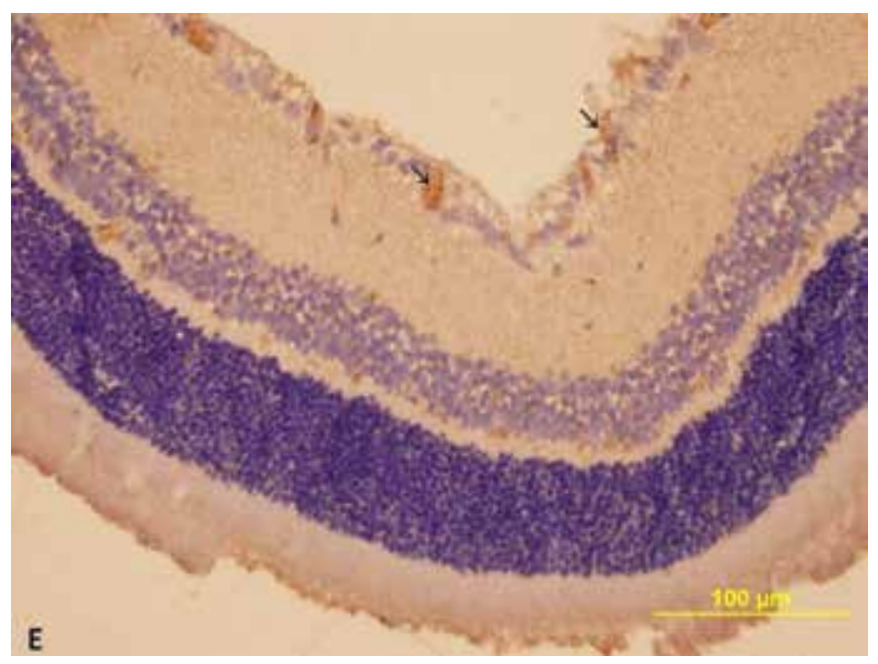

FIG. 5. GSL-1 staining in the cisplatin group. Animals were exposed to cisplatin and tissues stained with GSL-1. Similar to the sialic acid residues, GalNAc structures were also reduced by cisplatin.

an image software program. The mean intensity value for WGA staining in retina of control group was $169.91 \pm 5.92$. Compared to the control animals, the expression of GlcNAc residues in the retinas of rats given cisplatin decreased notably; this decrease in intensity value, from $169.91 \pm 5.92$ to $156.45 \pm 2.21$, was statistically significant $(\mathrm{p}<0.05)$ (Figure 8 ). In the Cisplatin+Selenium group however, similar to the control animals, cells localized in the inner plexiform and photoreceptor layers reacted strongly with biotin-labeled WGA (Figure 9). The mean intensity value for WGA staining in the Cisplatin+Selenium group was $162.53 \pm 2.61$ (Table 1).

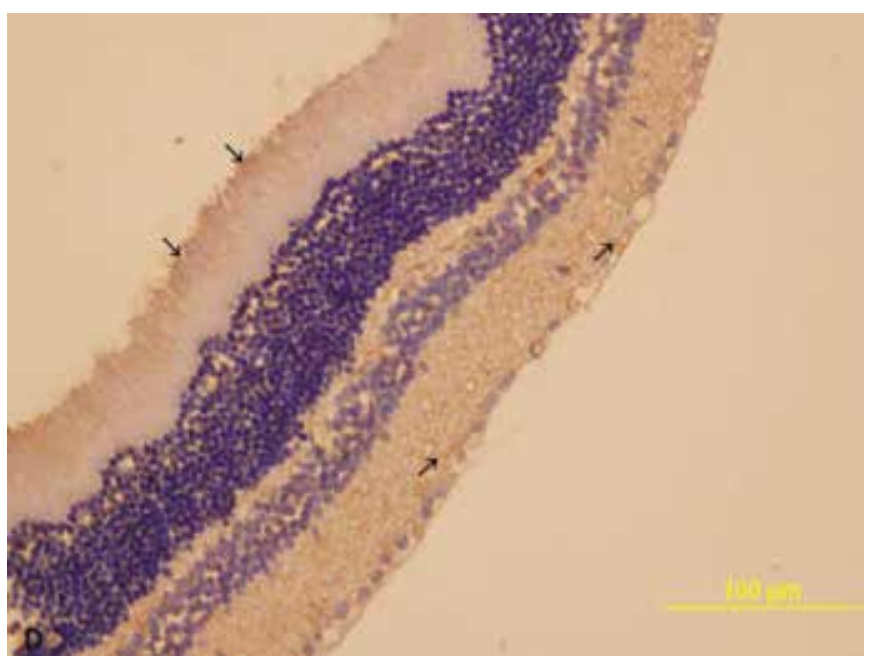

FIG. 4. GSL-1 staining in the control group. Tissues were stained with GSL-1. Binding sites for biotinylated GS-1 were relatively less frequent than binding sites for biotin-labeled MAA in all groups. In control animals, reactions with GSL-1 was evenly distributed throughout the rat retina.

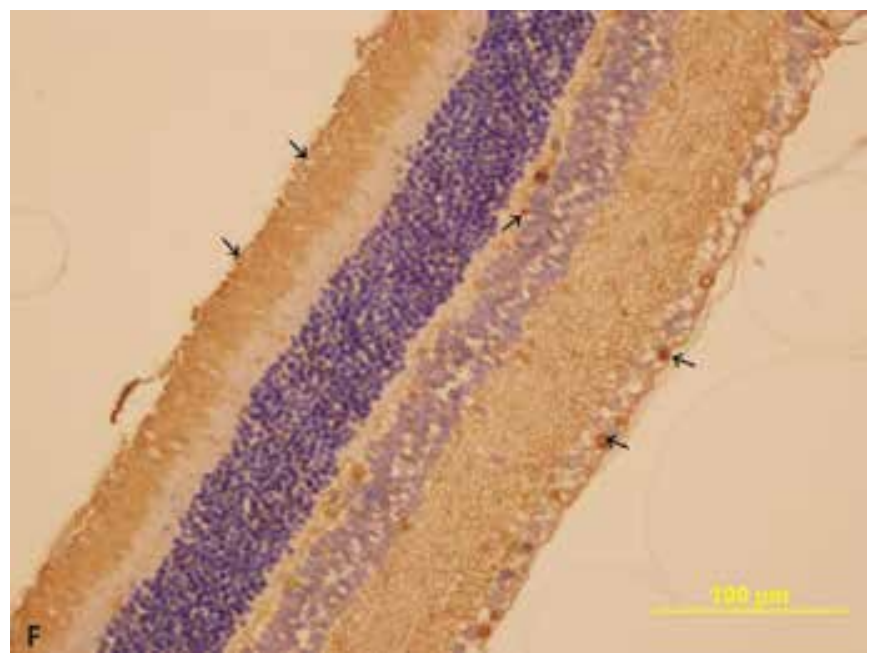

FIG. 6. GSL-1 staining in the cisplatin + selenium group. Tissues were stained with GSL-1. Similar to the sialic acid residues, GalNAc structures were also reduced by cisplatin and the adverse effects of cisplatin on the expression of GalNAc residues were mitigated by selenium.

\section{DISCUSSION}

In the human proteome, more than half of the known protein sequences can potentially be modified post-translationally via $\mathrm{O}$ - or N-linked glycosylation (20). To date, approximately 1000 proteins have been reported to be modified by the addition of carbohydrate residues in mammalian cells (21-23). Owing to the large number of structurally diverse target proteins, the nature of the regulatory processes governing protein glycosylation is not yet fully understood. 


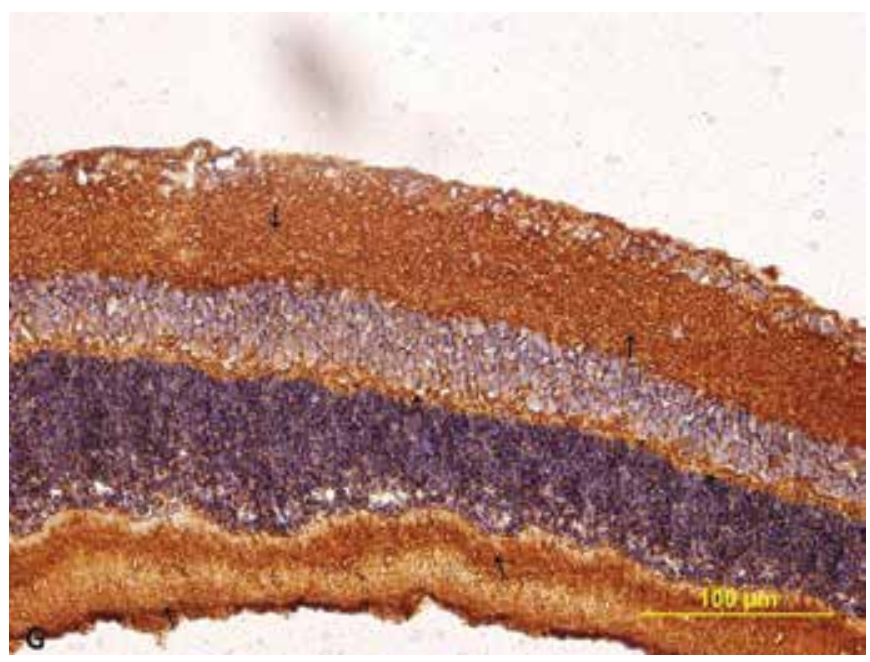

FIG. 7. WGA staining in the control group. Tissues stained with WGA. Histochemically, diffuse WGA staining of GIcNAc residues was observed throughout the retina of the control animals. In particular, cells localized in the inner plexiform and photoreceptor layers reacted strongly with biotin-labeled WGA.

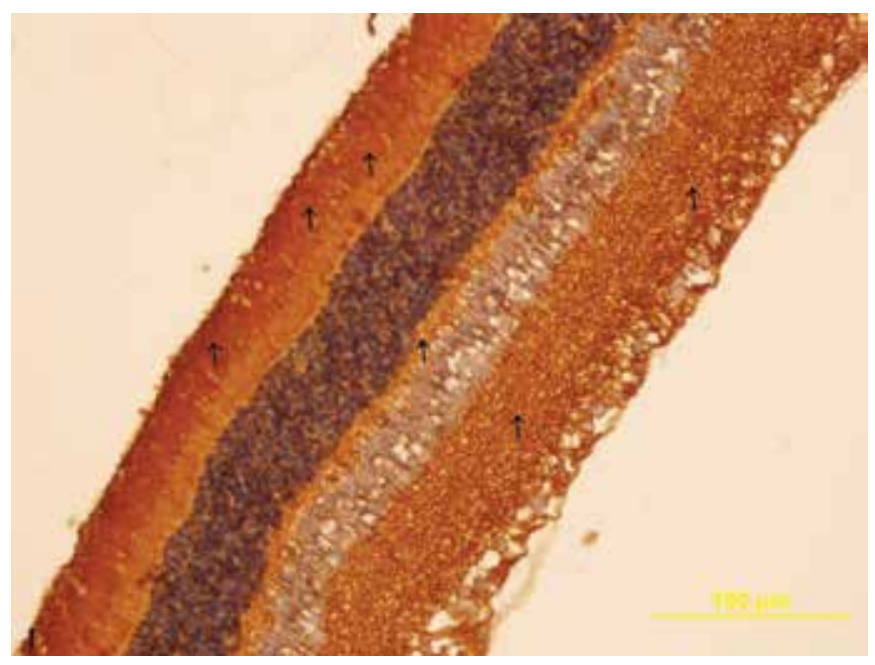

FIG. 9. WGA staining in the cisplatin + selenium group. Tissues were stained with WGA. In the cisplatin + selenium group, however, similar to the control animal cells localized in the inner plexiform and photoreceptor layers reacted strongly with biotin-labeled WGA.

Cisplatin is an important chemotherapeutic widely used in the treatment of cancer patients. This chemotherapeutic compound acts in various ways, such as via the formation of DNA adducts, the production of reactive oxygen species, increased lipid peroxidation and increased mitochondrial stress (14). When it affects normal tissue metabolism, side effects like ototoxicity, gonadotoxicity, nephrotoxicity, neurotoxicity and marrow suppression appear $(14,16)$. Many agents like pomegranate, mirtazapine, resveratrol and selenium have been used to prevent cisplatin toxicity in different organs $(17,24)$. The

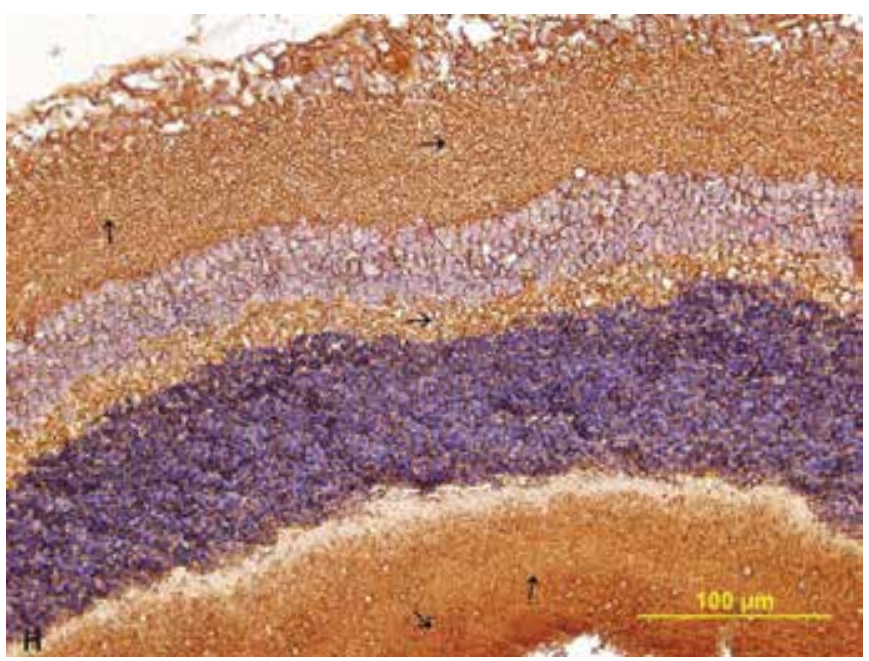

FIG. 8. WGA staining in the cisplatin group. Animals were exposed to cisplatin and tissues stained with WGA. Compared to control animals, the expression of GlcNAc residues in the retina of rats given cisplatin decreased notably.

retinotoxicity of cisplatin has not been studied extensively and is mostly reported as case reports with loss of vision at the end $(12,13,25)$. Selenium is an essential trace element that has direct or indirect antioxidant, neuroprotective effects and is reported to be effective in cisplatin-related toxicities. Selenium is incorporated into proteins to make selenoproteins, which are important antioxidant enzymes [especially, glutathione peroxidase (GSH-Px)]. The antioxidant properties of selenoproteins help prevent cellular damage from free radicals. Free radicals are natural by-products of oxygen metabolism that may contribute to the development of chronic diseases (26). Other selenoproteins help to regulate thyroid function and play a role in the immune system (27). Some studies have addressed the roles of selenoproteins in the eyes, with evidence suggesting that selenium supplementation may have a role in preventing cataract formation and age-related maculopathy, and also possess beneficial effects on diabetic retinopathy $(28,29)$. Se deficiency is a factor in preventing the activity of GSH-Px and increasing the free oxygen radicals in tissues, which leads to increased oxidative damage of the tissues. Se deficiency has effects by causing the reduction of lymphocytes and weakness of the immune system (26). We tried to determine the detrimental effects of cisplatin on some glycan structures in the rat retina and putative protective effects of selenium in retinal tissue.

GlcNAc and GalNAc are glycans that are essential for fundamental cellular processes such as transcription/translation, nuclear transport, protein stability and protein-protein interactions. The increased levels of GlcNAc and GalNAc in cancerous cells is associated with poor prognosis and likely enhanc- 
es tumor cell proliferation and invasion (25). Likewise, it is reported that the overexpression of sialic acid is a hallmark of some cancers and its expression has been correlated to metastasis and poor prognosis (30). The results of the present study showed that cisplatin reduced the expression of GlcNAc, GalNAc and $\alpha-2,3$-bound sialic acid structures on certain cell types. Taken together, it can be postulated that cisplatin acts as a chemotherapeutic agent by decreasing the GlcNAc, GalNAc and $\alpha-2,3$-bound sialic acid structures in cells. On the other hand, results of the present study showed that selenium inhibits GlcNAc, GalNAc and $\alpha$-2,3-bound sialic acid, reducing the effects of cisplatin. Numerous ways have been proposed concerning the effects of cisplatin as a chemotherapeutic agent. However, to date, there is no information to suggest that cisplatin may have anti-carcinogenic effects by decreasing cellular GlcNAc, GalNAc and $\alpha-2,3$-bound sialic acid structures. In addition, at first glance it could be considered that selenium protects cells from the adverse effects of cisplatin. However, it should be taken into consideration that concomitant use of selenium with cisplatin in cancer therapy may act as a doubleedged sword.

Recent studies revealed that cisplatin-induced cell death is blocked by sialic acid residues (30). In our previous study (24), we demonstrated that cisplatin induces apoptosis in rat retina. On the other hand, data obtained in the present study revealed that cisplatin decreased the sialic acid concentrations in rat retina. Furthermore, selenium administration inhibited the sialic acid reducing effect of cisplatin on rat retina. In light of these findings, we can conclude that cisplatin may induce apoptosis in the rat retina by decreasing cellular sialic acid.

In conclusion, cisplatin has detrimental effects on rat retina and reduces the sialic acid, GlcNAc and GalNAc levels in certain retinal cells. However, selenium prevents the reducing effect of cisplatin on sialic acid, GlcNAc and GalNAc residues in retinal cells. In the case of using cisplatin as a chemotherapeutic agent concomitantly with selenium, it should be taken into consideration that selenium may abolish the anticarcinogenic effect of cisplatin. Further studies are needed to determine the effects of cisplatin and selenium on cells.

Ethics Committee Approval: Ethics committee approval was received for this study from the Local Animal Ethics Committee (03/07/2013, 2013-13-94) and The Association for Research in Vision and Ophthalmology (ARVO) guidelines.

\section{Informed Consent: N/A.}

Peer-review: Externally peer-reviewed.
Author contributions: Concept - D.A., A.Y.; Design - D.A., H.A., E.S.S.; Supervision - A.K., S.S.E., K.S.; Resource - D.A., H.A.; Materials - D.A., A.Y., E.S.S.; Data Collection and/or Processing - D.A., A.Y., H.A., E.S.S., A.Y., O.Y., A.K., S.S.E., K.S.; Analysis and/or Interpretation - D.A., A.K., S.S.E., K.S.; Literature Search - D.A., H.A., E.S.S., A.Y.; Writing - D.A., H.A.; Critical Reviews - K.S., D.A., A.Y.

Conflict of Interest: No conflict of interest was declared by the authors.

Financial Disclosure: The authors declared that this study has received no financial support.

\section{REFERENCES}

1. Carlson BA, Yoo MH, Shrimali RK, Irons R, Gladyshev VN, Hatfield DL, et al. Role of selenium-containing proteins in Tcell and macrophage function. Proc Nutr Soc 2010;69:300-10. [Crossref]

2. Zhang ZW, Wang QH, Zhang JL, Li S, Wang XL, Xu SW. Effects of oxidative stress on immunosuppression induced by selenium deficiency in chickens. Biol Trace Elem Res 2012;149:352-61. [Crossref]

3. Rayman MP. The importance of selenium to human health. Lancet 2000;356:233-41. [Crossref]

4. Puertas MC, Martinez-Martos JM, Cobo MP, Carrera MP, Mayas MD, Ramirez-Exposito MJ. Plasma oxidative stress parameters in men and women with early stage Alzheimer type dementia. Exp Gerontol 2012;47:625-30. [Crossref]

5. Thuluvath PJ, Triger DR. Selenium in chronic liver disease. $J$ Hepatol 1992;14:176-82. [Crossref]

6. Franz H. Mistletoe lectins and their A and B chains. Oncology 1986;43:23-34. [Crossref]

7. Gabius HJ. Tumorlectinologie: Ein gebiet im schnittpunkt von zuckerchemie, biochemie, zellbiologie und onkologie. Angew Chem Int Edit 1988;100:1321-30. [Crossref]

8. Argueso P. Glycobiology of the ocular surface: mucins and lectins. Jpn J Ophthalmol 2013;57:150-5. [Crossref]

9. Bourrillon R, Aubery M. Cell surface glycoproteins in embryonic development. Int Rev Cytol 1989;116:257-338. [Crossref]

10. Summerfield JA. The role of human lectins in host defence. The Linacre Lecture 1991. J Roy Coll Phys Lond 1992;26:92-6.

11. Kostrominova TY. Application of WGA lectin staining for visualization of the connective tissue in skeletal muscle, bone, and ligament/tendon studies. Microsc Res Techniq 2011;74:18-22. [Crossref]

12. Shin T. The pleiotropic effects of galectin-3 in neuroinflammation: a review. Acta Histochem 2013;115:407-11. [Crossref]

13. Van der Ende J, Van Baardewijk LJ, Sier CF, Schipper IB. Bone healing and mannose-binding lectin. Int J Surg 2013;11:296300. [Crossref] 
14. Amin A, Buratovich MA. New platinum and ruthenium complexes-the latest class of potential chemotherapeutic drugs-a review of recent developments in the field. Mini-Rev Med Chem 2009;9:1489-503. [Crossref]

15. Gregg RW, Molepo JM, Monpetit VJ, Mikael NZ, Redmond D, Gadia M, et al. Cisplatin neurotoxicity: the relationship between dosage, time, and platinum concentration in neurologic tissues, and morphologic evidence of toxicity. J Clin Oncol 1992;10:795-803.

16. Yazici ZM, Meric A, Midi A, Arinc YV, Kahya V, Hafiz G. Reduction of cisplatin ototoxicity in rats by oral administration of pomegranate extract. Eur Arch Oto-Rhino-L 2012;269:45-52. [Crossref]

17. Ozbal S, Erbil G, Kocdor H, Tugyan K, Pekcetin C, Ozogul C. The effects of selenium against cerebral ischemia-reperfusion injury in rats. Neurosci Lett 2008;438:265-9. [Crossref]

18. Ognjanovi BI, Djordjevic NZ, Matic MM, Obradovic JM, Mladenovic JM, Stajn AS, et al. Lipid peroxidative damage on Cisplatin exposure and alterations in antioxidant defense system in rat kidneys: a possible protective effect of selenium. Int $\mathrm{J} \mathrm{Mol}$ Sci 2012;13:1790-803. [Crossref]

19. Rezvanfar MA, Shahverdi AR, Ahmadi A, Baeeri M, Mohammadirad A, Abdollahi M. Protection of cisplatin-induced spermatotoxicity, DNA damage and chromatin abnormality by selenium nanoparticles. Toxicol Appl Pharm 2013;266:356-65. [Crossref]

20. Wang PH. Altered sialylation and its roles in gynecologic cancers. J Cancer Mol 2006;2:107-16.

21. Roos MD, Hanover JA. Structure of O-linked GlcNAc transferase: mediator of glycan-dependent signaling. Biochem Bioph Res Co 2000;271:275-80. [Crossref]
22. Manning G, Whyte DB, Martinez R, Hunter T, Sudarsanam S. The protein kinase complement of the human genome. Science 2002;298:1912-34. [Crossref]

23. Copeland RJ, Bullen JW, Hart GW. Cross-talk between GlcNAcylation and phosphorylation: roles in insulin resistance and glucose toxicity. AJP Endocrinology and Metabolism 2008;295:E17-28. [Crossref]

24. Yazici A, Sari ES, Yay A, Akşit H, Kilic A, Akşit D, et al. The Protective Effect of Selenium in Cisplatin Related Retinotoxicity. Cutan Ocul Toxicol 2014;33:327-32. [Crossref]

25. Kamigaito T, Okaneya T, Kawakubo M, Shimojo H, Nishizawa O, Nakayama J. Overexpression of O-GlcNAc by prostate cancer cells is significantly associated with poor prognosis of patients. Prostate Cancer P D 2014;1:18-22. [Crossref]

26. Sadeghian S, Kojouri GA, Mohebbi A. Nanoparticles of Selenium as species with stronger physiological effects in sheep in comparison with sodium selenite. Biol Trace Elem Res 2012;146:302-8. [Crossref]

27. Bellinger FP, Raman AV, Reeves MA, Berry MJ. Regulation and function of selenoproteins in human disease. Biochem $J$ 2009;422:11-22. [Crossref]

28. Flohe L. Selenium, selenoproteins and vision. In: Nutrition and the eye ed. A, A. Karger; 2005.

29. Sheck L, Davies J, Wilson G. Selenium and ocular health in New Zealand. N Z Med J 2010;123:85-94.

30. Schultz MJ, Swindall AF, Wright JW, Sztul ES, Landen CN, Bellis SL. ST6Gal-I sialyltransferase confers cisplatin resistance in ovarian tumor cells. J Ovarian Res 2013;6:2-9. 